\title{
Scanning electron microscopic study of precipitation during aging of cast aluminium alloy-354
}

\author{
${ }^{1}$ B.Sudheer Reddy, ${ }^{2}$ B.N.V.Sudhakar, ${ }^{3}$ D.RaviTeja, ${ }^{4}$ P.Satya Kiran \\ School Of Mechanical and Building Sciences, VIT UNIVERSITY, Vellore-632014, Tamil Nadu, India
}

\begin{abstract}
The aim of this paper is to study evolution of precipitation during aging at different temperatures in cast aluminium alloy-354 grade. Scanning electron microscope (SEM) is used to examine these precipitates. Purpose of applying this technique of microscopic analysis was mainly to investigate the distribution, size and density of hardening precipitates as a function of aging temperature. The heat treatment of alloy comprises of, Solutionizing, quenching and aging. Tensile testing is carried out after aging at different temperatures and the resulting fractured piece is used for microscope analysis. The SEM images are used to compare precipitation at different aging temperatures. Tensile test results are generated after aging at different temperatures. The mechanical properties of the material are correlated with microstructure.
\end{abstract}

Key Words: Scanning Electron Microscope (SEM), Cast Alloy Al-354, Precipitate Distribution, Aging Treatment.

\section{Introduction}

In modern industry aluminium (Al) alloys have been widely used due to their light weight, high strength and good ductility. By applying proper heat treatments, the strength of $\mathrm{Al}$ alloys can be drastically increased through precipitation hardening, in which very small sized precipitates form in the Al matrix acting as important barriers for dislocation motion. Permanent mould cast 354 type AlSiCuMg alloys display high strength and hardness values after the application of suitable heat treatment, this improvement is a result due to presence of the hardening elements copper and magnesium. The corrosion resistant and the hot tearing tendency of these castings however are affected as a consequence of the presence of copper. The silicon content of this type of alloy improves its cast-ability and reduces shrinkage. These castings mainly hold great promise for structural applications because of their strength they attain after the application of suitable heat treatment. Because of this reason, 354 type castings have the ability of being used in the manufacturing of large scale parts and components in the automotive and aeronautical industries. Aluminium is widely used in making utensils, combs, collar buttons, toasters, mixtures, electrical conductors, food containers, paint, name plates, ash trays ,flower pots, coins etc. It is also used on transportation industry in the manufacture of bicycles, motorcycles, trucks and buses, aeroplanes and marine vessels.

Heat treatment is applied to $\mathrm{AlSiCuMg}$ alloys for the purpose of increasing their mechanical properties by number of micro structural changes, which takes place as a result of applying heat treatment regime and the important thermal treatment parameters i.e., temperature and time. This total treatment comprises three stages, solution heat treatment, quenching followed by aging. In aging treatment the castings are subjected to a particular temperature for a certain period of time. Aging temperature and time are the two parameters that control the characteristics of the phases precipitated during the heat treatment and finally the mechanical properties of the alloys. The influence of age hardening parameters, temperature and time on the tensile properties of 354 cast alloy is examined. Three aging temperatures are applied to the 354 alloy for an aging period of 5hours.

Many researches are carried out and various techniques including Scanning Electron Microscopic study [1], $\mathrm{X}$ ray diffraction [3], nuclear magnetic resonance, atom probe field-ion microscopy, differential scanning calorimeters [3-4], Transmission electron microscopy and high-resolution transmission electron microscopy [7] have been applied to characterize the strengthening precipitates in $\mathrm{Al}$ alloys. This scanning electron microscope is very limitedly used to visualize the small-sized precipitates in the Al-matrix due to following limitations.

Most of SEM instruments cannot resolve the structure information below $1 \mathrm{~nm}$. Therefore visualization of the precipitates in $\mathrm{Al}$ alloys approaches to the limit resolution of most SEM instruments. Specimen preparation is difficult in SEM, because it requires polishing and chemical etching. Some traces of scratches are left behind by polishing using mechanical means, sticky corrosive remainder precipitates are left behind by chemical etching, and precipitates of very small size cannot be visualized by SEM even with higher magnification. So without appropriate specimen preparation and sufficient resolution, small hardening precipitates cannot be observed in SEM. So in order to increase the chance of observing the small precipitates in SEM, special focus has to be paid during sample preparation. 


\section{Methodology}

Alloy 354 is prepared by melting $\mathrm{Al}$ alloy 356 and adjusting the weight percentage ratio. Alloy 356 melted in silicon carbide crucibles, silicon, copper and magnesium were added as pure form to the molten metal, in order to get the $\mathrm{Al}-9 \% \mathrm{Si}-1.8 \% \mathrm{Cu}-0.5 \% \mathrm{Mg}$. Any impurities in this molten metal removed using argon gas which is injected at a speed of 150rpm. The molten metal undergoes a process called casting, where this molten metal poured in to the moulds. The mould is pre heated to $738 \mathrm{k}$. Later heat treatment is carried out in three steps: first solutionizing, second quenching and finally aging. Solutionizing is carried out by placing the specimen in air forced furnace at $785 \mathrm{k}$ for 12 hours. Quenching is carried out by placing the solutionised specimen in warm water at a temperature of $333 \mathrm{k}$. Aging is carried out by heating the obtained specimen in air forced furnace at different temperatures for 5 hours of aging time. Tensile strength is carried out for the heat treated bars using Material Testing System (MTS). Specimen is held by suitable means between the two heads of a testing machine and subjected to a progressively increasing strain rate of around $1 \mathrm{X} 10-4 / \mathrm{sec}$. Three tensile test bars of various aging temperatures were tested in order to interpret the tensile properties.

In order to evaluate the characteristics of precipitates a Scanning Electron Microscope (SEM) is used. The Purpose of applying this technique of microscopic analysis was mainly to investigate the distribution, size and density of hardening precipitates as a function of aging temperature and time. In SEM the electrons interact with atoms in the sample, producing various signals that can be detected. This electron beam gets reflected at an angle of incidence of about $1^{\circ}$. They contain information about the sample's surface and composition. Such a microscope which produces images from the reflected beam is called Scanning Electron Microscope (SEM). The electron beam is generally scanned in a raster scan pattern. The beam's position is combined with the detected signal to produce an image. SEM can achieve resolution better than 1 nanometre. The SEM used in the current study was SUPRAA 55 ZEISS SEM attached to OXFORD PENTA FEM system designed for image acquisition and energy dispersive X-ray (EDX) analysis. The SEM was operated at a voltage of $20 \mathrm{kV}$ with a maximum filament current of $2.40 \mathrm{~A}$.

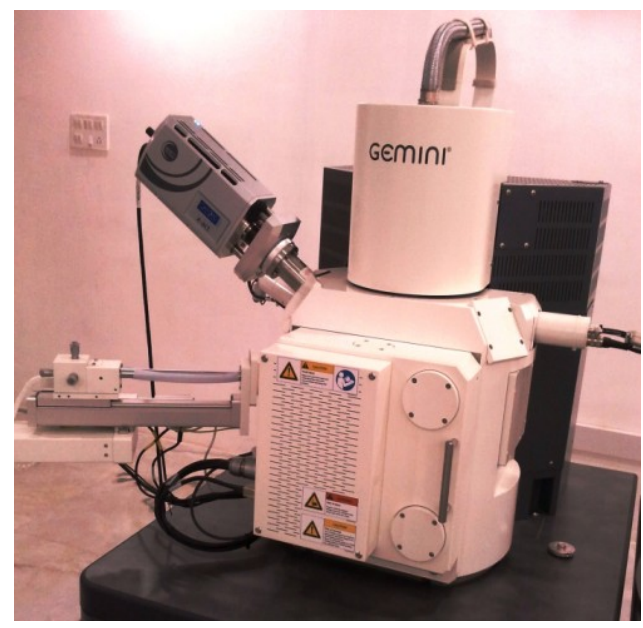

\section{Principle}

SEM produces different signals which include secondary electrons, back-scattered electrons rays, cathode luminescence light, and specimen current and transmitted electrons. Secondary electron detectors are standard equipment in all SEMS. The common mode of detection is when an electron beam is acted on an atom, secondary electrons are emitted by it. The angle between the surface and the beam controls the flow of secondary electrons. On a flat plane, the plume of secondary electrons is mostly contained by the sample, but on a tilted plane, the plume is partially exposed to rays, and results in emission of more electrons. By scanning the sample and detecting the secondary electrons, an image displaying the tilt of the surface is created. A wide range of magnifications is possible, from about 10 times to $>500,000$ times, about 250 times the magnification limit of the best light microscopes. 


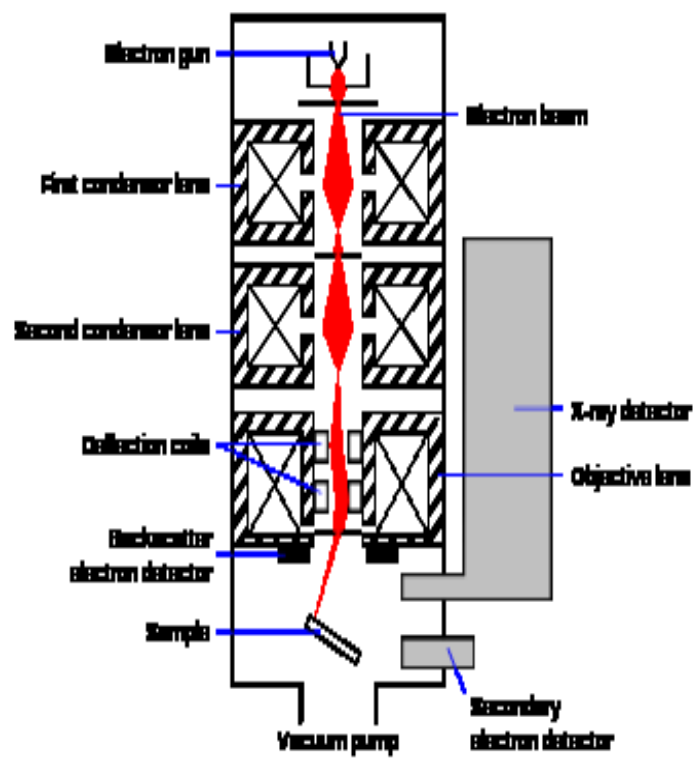

Samples were grinded and polished to produce a clear mirror like surface finish and then further subjected to chemical micro etching process. The etching reagent used for this study consists of $0.5 \mathrm{~mL} \mathrm{HF} 48 \%$, i.e., a solution of $0.5 \mathrm{~mL} \mathrm{HF}$ of a $48 \%$ concentration with the remaining $99.5 \mathrm{~m} \mathrm{~L}$ being water. This etchant was applied to the samples at room temperature for a time ranging from a few seconds to a few minutes based on the chemical composition of the alloy and the heat treatment procedures are applied to them for further investigation.

\section{Results And Discursions}

Given Casting are subjected to solution treatment followed by quenching. The quenched casting is subjected to Age hardening at different aging temperatures for certain period of time. The excess solute atoms in the SSS of $\alpha$-Al ultimately come out after certain duration depending on applied temperature to the castings. During the treatment, solute atoms diffuse from supersaturated structure towards high energy sites as grain and phase boundaries. The vacant sites in lattice are produced by solutionizing and quenching processes. It is the main reason for diffusion of excess solute atoms through the metal matrix. These vacancies have a great effect on the diffusion of the precipitation of the 2nd-phase particles. The hardening elements in Al 354 alloy are, copper, magnesium, and silicon. To form the precipitates the aging treatment is applied. No particular phase is formed in Al-354 alloy precipitation hardening because it is complicated. Variety of phases with different combination of all the elements in alloy is possible. By aging the specimens at different temperatures for a period of 5 hours. We obtain different tensile strengths which are tabulated below. Maximum tensile strength is obtained by aging the specimen at temperature of $188^{\circ} \mathrm{C}$ and minimum can be obtained at $171^{\circ} \mathrm{C}$.

\begin{tabular}{|l|l|}
\hline $\begin{array}{l}\text { Specimen(temper } \\
\text { ature) }\end{array}$ & $\begin{array}{l}\text { Ultimate tensile strength } \\
(\mathrm{MPa})\end{array}$ \\
\hline 188 & 415 \\
\hline 177 & 405 \\
\hline 171 & 402 \\
\hline
\end{tabular}

Ostwald ripening is a phenomenon in which precipitates size can be related to aging parameters i.e., temperature and time. Large precipitates are favourable to develop from smaller precipitates. The small precipitates are unstable and finally dissolve completely. We know large precipitates are much stable energetically than small precipitates. It is obtained by the fact that molecules on the surface of a particle possess less energy than other which are located inside and well packed. The distance between precipitates increases due to growth of large precipitates from small precipitates. The size of precipitates is main reason for the strength properties.

According to Orowan Bowing mechanism, the stress required to force a dislocation is inversely proportional to particle separation or spacing. From this we can deduct that if the distance between the precipitates is large then the stress required to fracture the specimen is less and thus low ultimate tensile strength. If the distance between precipitates is small then the stress required to fracture the specimen will be high and thus high ultimate tensile strength. So inter particle spacing plays vital role. 
After the completion of work specimen is observed under the SEM. The images obtained vary according to the magnification that ranges from 100X-100000X. We can see the silicon precipitates clearly but the precipitates of $\mathrm{AlCuMgSi}$ for which we are looking cannot be resolved clearly at this aging temperatures and magnifications. As we cannot locate images of precipitates at a maximum temperature we can't get images at low temperature also.so we need to move for further investigation and the experiment should be carried out by using Transmission Electron Microscope for clear resolution of precipitates.

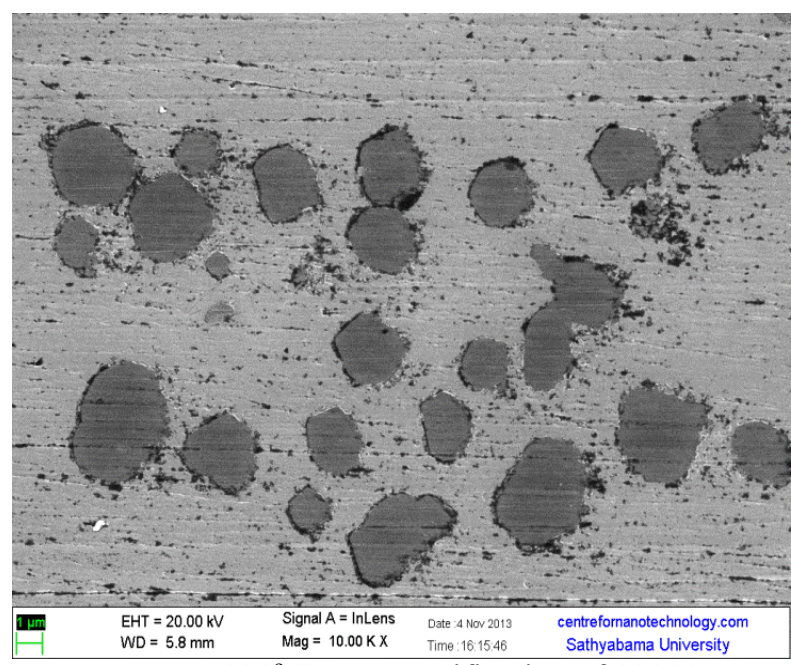

Images at $188^{\circ} \mathrm{C}$ at a magnification of $10000 \mathrm{X}$

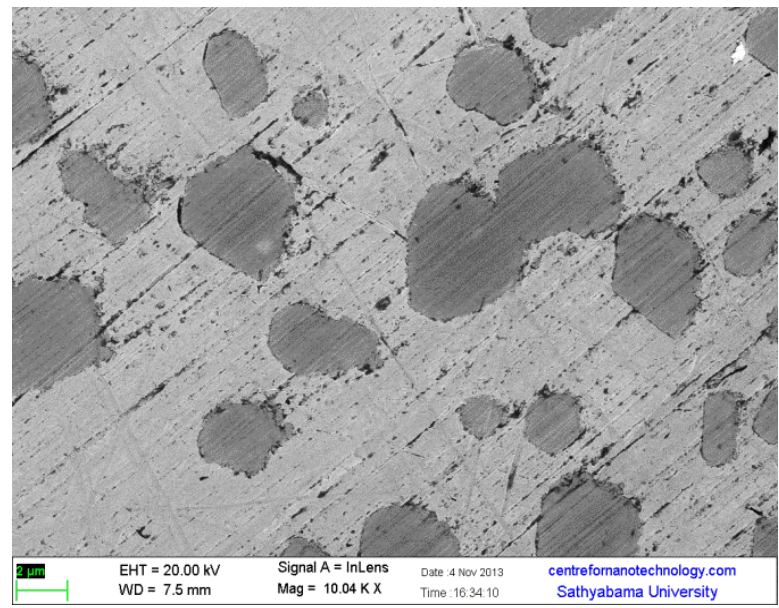

Images at $177^{\circ} \mathrm{C}$ at a magnification of $10000 \mathrm{X}$

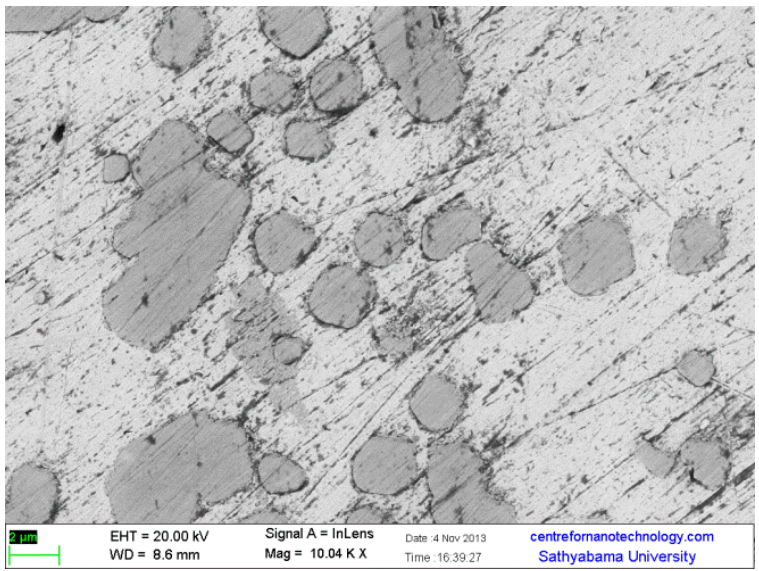

Images at $171^{\circ} \mathrm{C}$ at a magnification of $10000 \mathrm{X}$ 


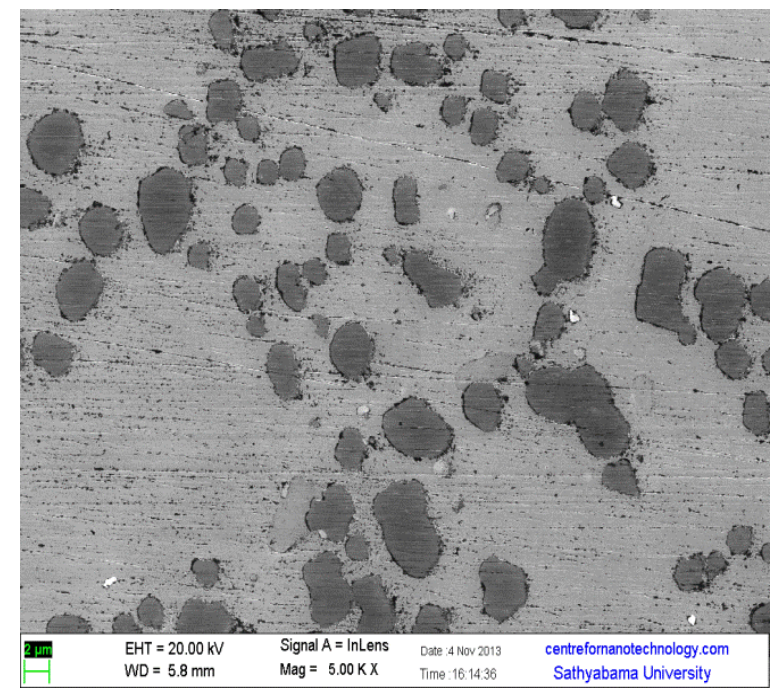

Images at $188^{\circ} \mathrm{C}$ at a magnification of $5000 \mathrm{X}$

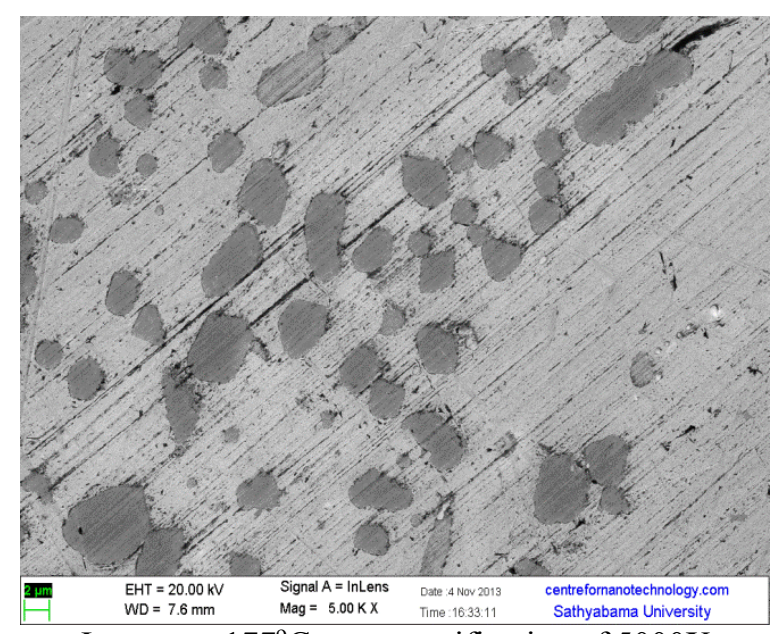

Images at $177^{\circ} \mathrm{C}$ at a magnification of $5000 \mathrm{X}$

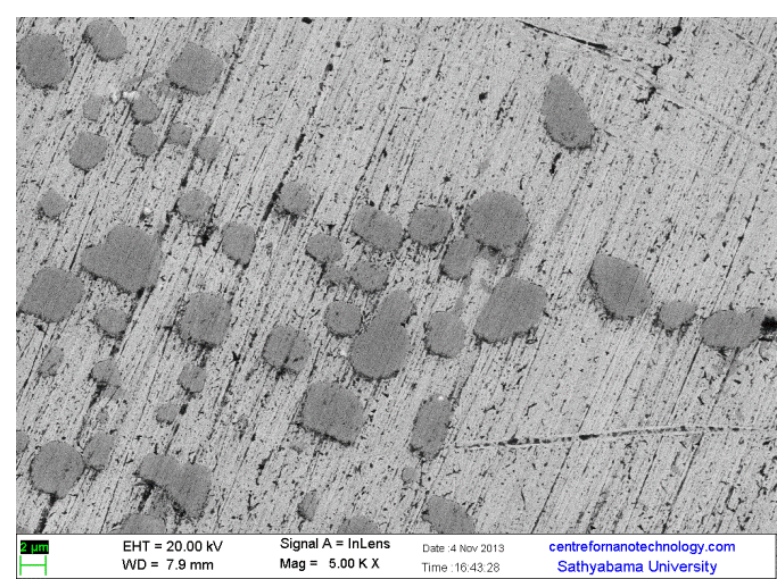

Images at $171^{\circ} \mathrm{C}$ at a magnification of $5000 \mathrm{X}$ 

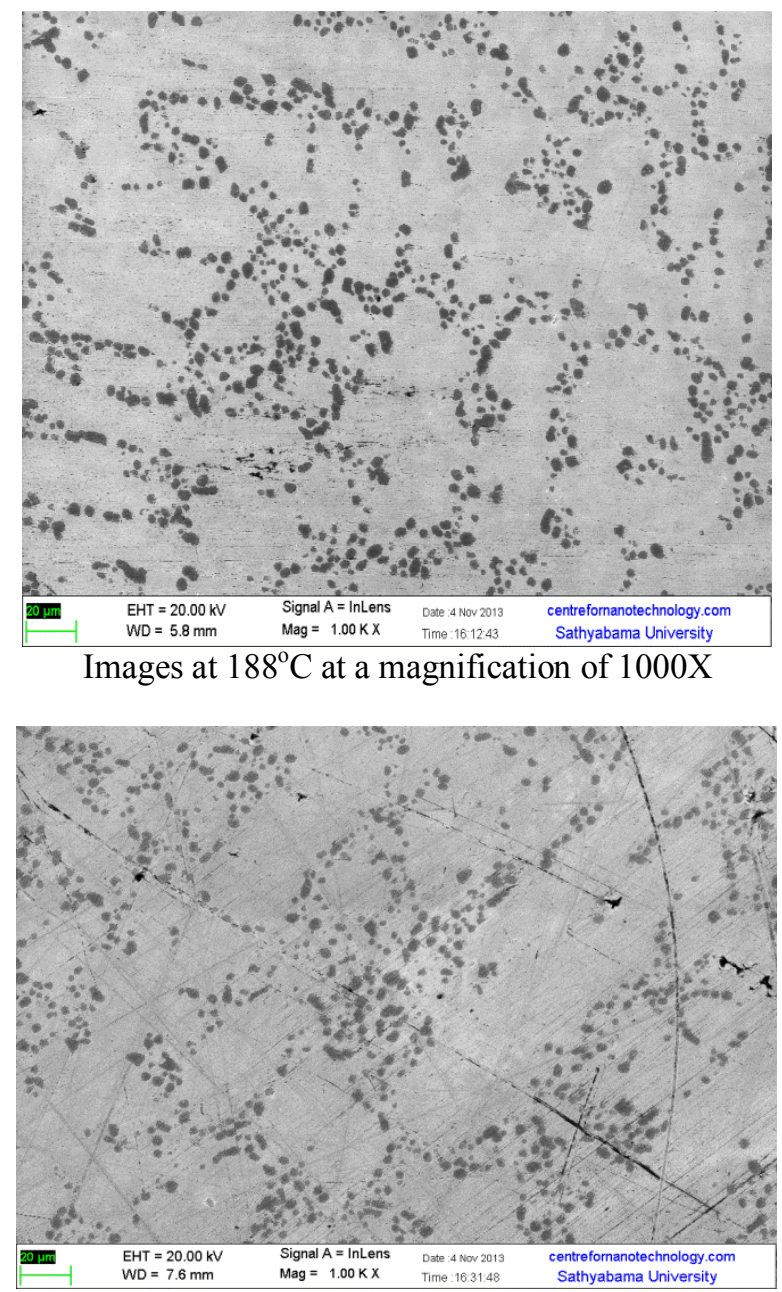

Images at $177^{\circ} \mathrm{C}$ at a magnification of $1000 \mathrm{X}$

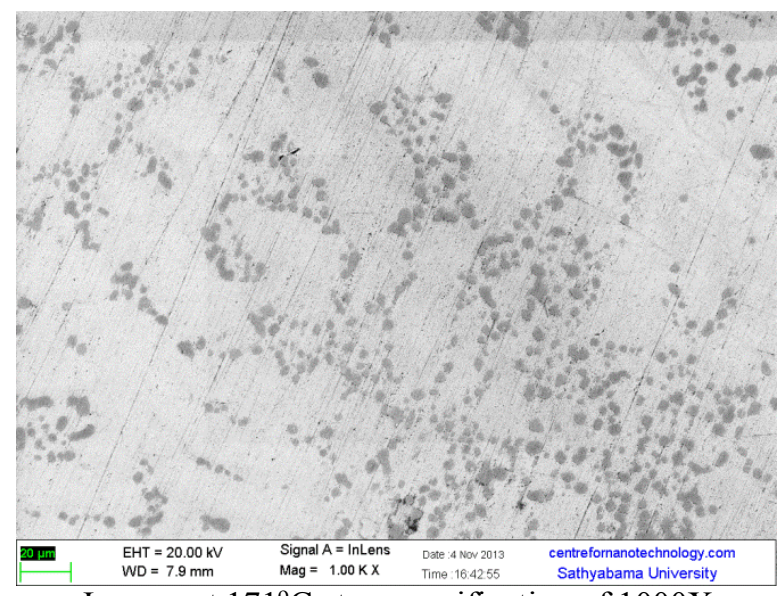

Images at $171^{\circ} \mathrm{C}$ at a magnification of $1000 \mathrm{X}$ 


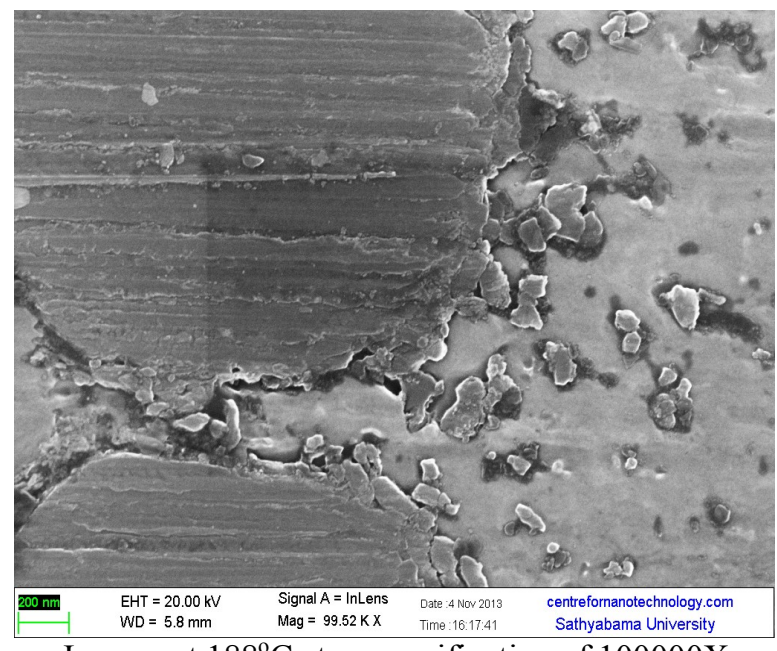

Images at $188^{\circ} \mathrm{C}$ at a magnification of $100000 \mathrm{X}$

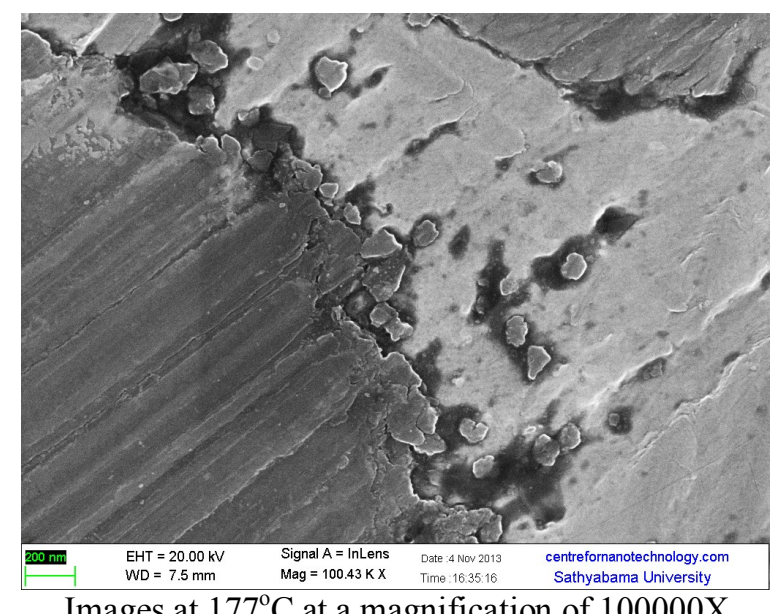

Images at $177^{\circ} \mathrm{C}$ at a magnification of $100000 \mathrm{X}$

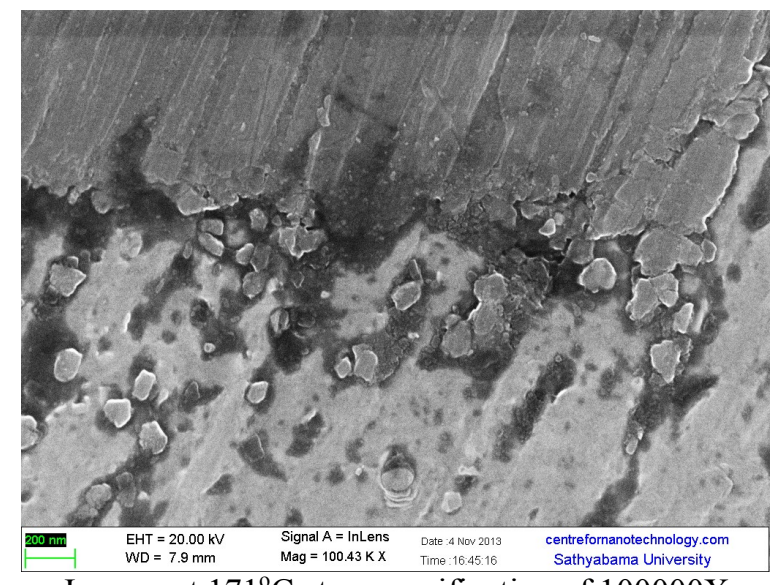

Images at $171^{\circ} \mathrm{C}$ at a magnification of $100000 \mathrm{X}$

\section{Conclusions}

1. Tensile strength of 354 type castings can be altered by aging parameters i.e., temperature and time.

2. If Aging treatment is done at higher temperature then there will be reduction in tensile properties.

3. Aging at low temperature $(171 \mathrm{~K})$ is observed to have high tensile strength.

4. No precipitates are visible even at higher magnifications.

5. No precipitates can be found at temperature of $188^{\circ} \mathrm{C}$, we can observe only silicon particles embedded in aluminium.

6. So we could not resolve the precipitates by using SEM at magnification up to $100000 \mathrm{X}$, because the precipitates are very small that cannot be captured by using SEM. 
7. As we cannot see the precipitates at $188^{\circ} \mathrm{C}$, we cannot obtain satisfactory results at lower temperatures of $177^{\circ} \mathrm{C}$ and $171^{\circ \mathrm{C}}$

8. For further examination of accurate resolution of precipitates we need to look for TEM microstructure study.

\section{References}

[1]. H.R. Ammar, A.M. Samuel, F.H. Samuel, E.Simielli,G.K. Sigworth ,J .C. Lin: "Influence Of Aging Parameters On The Tensile Properties And Quality Index Of Al-9 Pct Si-1.8 Pct Cu-0.5 Pct Mg 354-Type Casting Alloys” The Minerals, Metals \& Materials Society And ASM INTERNATIONAL 2011 DOI: 10.1007/S11661-011-0808-7.

[2]. R.C.Lemon And C.R.Hewie,AFS Trans.,1963,Vol .70, Pp.465-70.

[3]. J.G.Kaufman And E.L.Rooy: Aluminium Alloys "Castings,Properties,Processingand Applications", ASM INTERNATIONAL, Materials Park, OH, 2004, Pp, 31-32 \& 69-131.

[4]. X.Q.Jhao,M.J.Shi,J.H.Chen, S.B Wang, C.H.Liu, C.L.Wu: “A Facile Electron Microscopy Method For Measuring Precipitate Volume Fraction In Al Cu Mg Alloys" ELSEVIER Inc 2002.DOI: 10.1016/J.Matchar.2012.04.009.

[5]. N.Chomsaeng,M.Haruta, Chairuangsri,H.Kurata, S.Isoda, M.Shiojiri :"H R TEM And ADF-STEM Of Precipitates At Peak-Ageing In Cast A365 Aluminium Alloy”. ELSEVIER 2010 Inc DOI: 10.1016/J.Jallcom.2010.02.084.

[6]. V.D.Kodgire, S.V. Kodgire: “Material Science And Metallurgy For Engineers”.P 304-306, P 498-501.

[7]. Ringer SP,Hono K.Microstructural Evolution And Age Hardening In Aluminium Alloys: Atom Probe Field-Ion Microscopy And Transmission Electron Microscopy Studies. Mater Charact 2000; 45:101-31.

[8]. Bastow TJ, Celotto S. Clustering And Formation Of Nano-Precipitates In Dilute Aluminium And Magnesium Alloys. Mater Sci Eng 2003; C23:757-62. 